\title{
The role of lasers in modern urology
}

\author{
Łukasz Dołowy, Wojciech Krajewski, Janusz Dembowski, Romuald Zdrojowy, Anna Kołodziej \\ Department of Urology and Oncological Urology, Wrocław Medical University, Wrocław, Poland
}

Citation: Dołowy Ł, Krajewski W, Dembowski J, Zdrojowy R, Kołodziej A. The role of lasers in modern urology. Cent European J Urol. 2015 ; 68: 175-182.

Article history

Submitted: Jan. 6, 2015

Accepted: April 17, 2015

Published on-line:

June 18, 2015
Corresponding author Wojciech Krajewski Medical University Department of Urology and Oncological Urology 213, Borowska Street 50-556 Wrocław, Poland phone: +48717331010 wk@softstar.pl
Introduction The functioning of modern urological departments and the high level of service they provide is possible through, among other things, the use of modern laser techniques.

Material and methods Open operations have been replaced by minimally invasive procedures, and classical surgical tools by advanced lasers.

The search for new applications with lasers began as technology developed. Among many devices available, holmium, diode and thulium lasers are currently the most popular.

Results Depending on the wavelength, the absorption by water and hemoglobin and the depth of penetration, lasers can be used for coagulation, vaporization and enucleation. In many centres, after all the possibilities of pharmacological treatment have been exhausted, lasers are used as the primary treatment for patients with benign prostatic hyperplasia, with therapeutic results that are better than those obtained through open or endoscopic operations. The use of lasers in the treatment of urolithiasis, urinary strictures and bladder tumours has made treatment of older patients with multiple comorbidities safe, without further necessity to modify the anticoagulant drug treatment. Laser procedures are additionally less invasive, reduce hospitalization time and enable a shorter bladder catheterization time, sometimes even eliminating the need for bladder catherterization completely. Such procedures are also characterized by more stable outcomes and a lower number of reoperations.

Conclusions There are also indications that with the increased competition among laser manufacturers, decreased purchase and maintenance costs, and increased operational safety, laser equipment will become mandatory and indispensable asset in all urology wards.

\section{Key Words: urology « lasers «` bladder outlet obstruction}

\section{INTRODUCTION}

In the last two decades laser techniques have become an increasingly popular method of treatment for patients with benign prostatic hyperplasia, bladder tumours, urolithiasis, urinary tract strictures or lesions of the external genitalia. The first reported use of laser technique in urology was published by Staethler in 1976 [1]. Some of initially introduced laser procedures had to be modified or abolished because of numerous postoperative complications, the need for prolonged catheter maintenance and because of unpredictable therapeutic effects. Nowadays due to equipment advancement, better understanding of urologists' needs on the part of producers, and growing experience of the operators laser treatments are a favourable alternative to traditional surgical procedures. Increasing accessibility to the appropriate equipment, relatively short learning curve and promising therapeutic effects has caused a growing interest in these methods. The results of longer than average survival time are seen in older patients with coexisting cardiac disorders requiring anticoagulant prevention. For those patients laser technique is frequently much safer treatment than classic operation. There are a lot of advantages of laser procedures over traditional surgeries. First, there is a grater precision and accuracy. Secondly lasers procedures are less invasive, lasers energy heat-seals blood vessels and in result there is less bleeding, swelling, pain, 
or scarring. Third, laser procedures are good alternative for patients with high comorbidity who are not suitable for open operations. Furthermore laser operating and hospitalization time may be shorter, more procedures may be done in outpatient settings. On the other hand some disadvantages of laser operations should be also taken into account. First of all not many doctors are trained to use lasers. Additionally laser equipment is expensive and unwieldy and it should also be remembered that strict safety precautions must be followed in the operating room when lasers are used.

Laser, which name comes from the first letters of the words in a phrase "Light Amplification by Stimulated Emission of Radiation", is a tool that emits monochromatic light. The light source may include gas, crystal, semiconductor or dye.

The interaction between the laser beam and the tissue depends on physical phenomena, such as reflection, dispersion and absorption. Some part of laser radiation is reflected, therefore useless for surgical purposes. Additionally, reflected light can cause unintended thermal damage to surrounding areas. From a medical perspective, the most important phenomenon is the absorption of the laser light by chromophore, on which the light is converted into thermal energy. The light in tissues is absorbed by haemoglobin, water or melanin. Depending on the temperature the tissue is heated, hance undergoes coagulation or vaporization. In case of a low tissue absorption coefficient the laser beam penetrates deeper, whereas a high absorption coefficient results in shallow penetration. The effect, however, is not only medium-dependent. The wavelength of the laser also plays an important role. For lasers emitting shorter wavelengths, a greater amount of energy is converted into heat [2].

Laser lithotripsy generally involves two basic mechanisms, photomechanical and photothermal. Photothermal lithotripsy produces small fragments and is effective in all stone compositions, whereas photomechanical lithotripsy produces larger fragments and is not effective in calcium oxalate monohydrate and cysteine stones. Photomechanical laser lithotripsy occurs because of the production of transient stress waves from the deposition of laser energy. An example of photomechanical mechanism is formation of cavitation bubble. It occurs when pulsing types of lasers are used. A cavitation bubble is caused by rapid expansion of water vapour at the laser fiber tip. The bubble then rapidly collapses releasing very strong pressure waves which causses stone fragmentation [3]. Another photomechanical mechanism is production of plasma on the fiber tip. It occurs with extremely short puls duration $(<500 \mathrm{~ns})$. Due to plasma instability, its fast expansion and contraction produce pressure waves that can disrupt stone [4]. Photothermal lithotripsy may occur either by direct absorption of protons and thermal stone disruption or by water within the stone rapidly heating and causing fast vapour flow that disrupts the stone [5].

\section{Lasers types}

Currently, the most commonly used lasers in urology are KTP:YAG (Potassium titanyl phosphate), LBO:YAG (lithium borate), diode lasers, Holmium (Ho):YAG and Thulium (Tm):YAG lasers. In the past many other types were used, however, due to a large number of complications, their use was discontinued $[2,6,7]$.

\section{Characteristics of particular individual lasers}

The Nd:YAG laser was the most commonly used laser in the past and therefore is the most studied one. It is characterized by more than $1 \mathrm{~cm}$ tissue penetration and by $1064 \mathrm{~nm}$ wavelength. It causes deep coagulative necrosis and considerable thermal tissue injury. Nd:YAG laser can be used for non-contact 'visual laser ablation of the prostate' (VLAP), contact ablation or interstitial laser coagulation (ILC) of the prostate. Oedema occurring after procedure frequently leads to irritative lower urinary tract syndrome (LUTS) and urinary retention, which often requires long-time catheterization.

Ho:YAG laser is a pulsed type of laser that emits energy absorbed by the water. It is characterized by wavelength of $2140 \mathrm{~nm}$ and pulse duration of $350 \mathrm{~ms}$. The depth of penetration in the prostate tissue is only $0.4 \mathrm{~mm}$. Therefore the depth of necrosis and thermal damages is limited. Ho-laser causes rapid coagulation of small and medium-sized vessels to the depth of about $2 \mathrm{~mm}$. Because this laser requires contact with the tissue, prostate can be precisely incised, dissected and enucleated. Ho-laser is mainly used for procedures on the prostate, in lithotripsy, ablation of urothelial tumours and for upper and lower urinary tract strictures incision [8].

KTP: YAG laser, also called green light laser, is derived from Nd: YAG laser. Passing the invisible Nd:YAG beam via a KTP crystal, doubles the frequency and halves the wavelength from $1064 \mathrm{~nm}$ to $532 \mathrm{~nm}$. Its energy is selectively absorbed by haemoglobin, but not by water. The penetration depth is about $0.8 \mathrm{~mm}$. It is characterized by a very good coagulation effect, which results in a good control of haemostasis. Because energy of KTP laser is absorbed only by haemoglobin, it is possible to perform operations in noncontact use called photoselective 
vaporization of tissue. Due to shallow absorption rate, necrosis of the tissue localized beneath the vaporized area is limited. An additional advantage is an almost bloodless course of the procedure.

The Tm:YAG laser produces continuous, $2000 \mathrm{~nm}$ wave. As in Ho-laser, energy is absorbed only by water and slightly shorter wavelength of thulium laser decreases the depth of penetration to $0.25 \mathrm{~mm}$. The Tm-laser is used for transurethral vaporization, enucleation or resection of the prostate.

The lithium triborate (LBO) laser is derived from KTP-laser. The wavelength of both lasers is equal. However, LBO-laser has an accelerated and a more efficient energy transfer and enhanced working distance (from $0.5 \mathrm{~mm}$ for KTP to $3 \mathrm{~mm}$ for LBO) [9]. A significant disadvantage of this laser is a marked decrease in haemostatic ability in comparison to KTP laser [10].

Diode lasers have been available for long time, yet, their clinical application has been limited. Diode lasers emit a beam of wavelength between 940 to $1470 \mathrm{~nm}$. Their energy is absorbed by both water and haemoglobin. As a result, good haemostatic and vaporisative effects are obtained [2]. Data regarding the penetration depth of diode lasers differs considerably between particular reports. Some reports on a $980 \mathrm{~nm}$ diode laser demonstrate its better haemostatic effect during prostate vaporization in comparison to $120 \mathrm{~W}$ LBO laser, however, higher incidence of complications, such as postoperative irritative symptoms and epididymitis, is noted [11].

\section{Laser applications in treatment of patients with bladder outlet obstruction}

Moderate-to-severe lower urinary tract symptoms in patients with benign prostatic hyperplasia $(\mathrm{BPH})$ appear in about one quarter of men in their $50 \mathrm{~s}$, one third of men in their $60 \mathrm{~s}$, and about half of all men in the eight decade of life [12].

Surgical procedures used in these patients include classical methods, such as TURP (transurethral resection of the prostate) and adenomectomy, as well as lasers techniques. In the United States laser techniques treatments are used in approximately $60 \%$ of patients with $\mathrm{BPH}$ or BPO (benign prostatic obstruction) after all the possibilities of pharmacological treatment have been exhausted $[13,14]$. The use of different lasers types allows the performance of $\mathrm{BPH} / \mathrm{BPO}$ ablation, enucleation, coagulation and vaporization. Mortality, necessity of reoperation, requirement of blood transfusion after surgery, as well as the number of water poisonings, is dependent on the volume of the removed prostatic gland and the duration of the procedure. The number of com- plications increases significantly in cases in which prostate is greater than $60 \mathrm{ml}$ and when the operation time exceeds one hour. The need for reoperation after TURP and adenomectomy during 8 years of follow-up observation (re-TURP, bladder neck incision, urethrotomy) is 14.7 and $9.8 \%$ respectively [15]. Perioperative complications after laser prostate treatments occur in approximately $20 \%$ of patients, however, $80 \%$ of these complications are considered low-grade (Clavien grade I-II) [16]. In addition, laser treatments are performed in $0.9 \% \mathrm{NaCl}$ environment, so transurethral resection syndrome, which occurs in $1.4 \%$ pts. after TURP, does not occur after laser techniques $[15,17]$.

For patients who have been qualified for the surgery (TURP/open procedure) with underlying cardiac and neurological diseases and receive oral anticoagulants the standard procedure is withdrawal of anticoagulant therapy 5-7 days prior to the procedure and administration of low molecular weight heparin injections. This treatment is commonly maintained for a period of seven days after surgery. The use of heparin protects from vein thrombosis incidents, however, there is an increased risk of intra- and postoperative bleeding. Patients after percutaneous coronary intervention with stent implantation are particularly vulnerable to thrombotic events and those who received metal stents should continuously receive dual antiplatelet therapy (aspirin + clopidogrel) for 4 weeks after surgical interventions. In cases of drug-eluting stents, therapy should last the minimum of 6 months [18].

In randomized study, which compared KTP laser PVP (Photo-Selective Vaporization of the Prostate) and TURP, operation time, especially among less experienced operators and when adenomas were larger than $80 \mathrm{ml}$, was 30-50 min longer in the laser group [19]. When LBO laser (120W) was used the difference decreased to 9 min $[19,20]$. Longer time of laser procedure is compensated by lower amount of blood loss $(0.45 \mathrm{~g} / \mathrm{dl}$ vs. $1.46 \mathrm{~g} / \mathrm{dl})$ [21]. In a study comparing LBO laser PVP with TURP, blood transfusion was not required in most cases after laser procedures. When compering blood loss after laser operation and after classic adenomectomy the difference is even more evident. An average $8.1 \%$ of patients after TURP, and even $13.3 \%$ after adenomectomy, require red blood cells transfusion [20, 22, 23]. Other randomised trial, which compared PVP with GreenLight120-W laser and TURP in prostates smaller than $80 \mathrm{cc}$, has been recently published. The authors claim that postoperative functional improvements were durable and equivalent in the two groups. Both techniques had a similar complication rate, however, hospital stay after laser procedure was significantly 
shorter [24]. Early outcomes of new 180-W XPS GreenLight laser system have been recently reported. They reveal that photoselective vaporization of the prostate (PVP) seems to be a safe and effective procedure and could play an important role in the surgical treatment of symptomatic BHP patients with larger prostate volumes [25, 26, 27]. In the study that compared holmium laser transurethral incision of the prostate and green light photoselective vaporization of the prostate it has been shown that both methods seem to be equally effective, safe and durable surgical treatment options for small prostates even in high risk patients [28].

An alternative method is vaporization with diode lasers, however, usage of these lasers must be carefully considered due to the numerous postoperative complications, such as bladder neck stenosis, the need for reoperation, formation of stones, strictures of the urethra or the occurrence of stress urinary incontinence $[11,29]$. In the study comparing diode laser with TURP authors have shown that diode laser vaporization $(980 \mathrm{~nm})$ offers a safe and feasible procedure in the management of patients with symptomatic benign prostatic hypertrophy, however, at longer follow-up the functional outcome of diode laser vaporization has been less efficient than TURP [30]. Other study comparing vaporization of the prostate with green light laser and diode laser presented no significant difference between improvement of voiding and micturition parameters. However, a significantly higher reoperation rate was observed in the diode group due to obstructive necrotic tissue, bladder neck and persisting or recurrent adenoma. Careful clinical application of diode laser type is warranted by authors [29].

Next device used in patients with narrowing of bladder neck/BPH is holmium laser. Possible procedures include ablation (HoLAP), enucleation (HoLEP) and resection (HoLRP) of prostate. Laser with power of $60 \mathrm{~W}, 80 \mathrm{~W}$ and $100 \mathrm{~W}$ are currently in use. In case of procedures performed with $60 \mathrm{~W}, 80 \mathrm{~W}$ lasers treatment results are comparable with those obtained after TURP [31, 32]. HoLRP should be performed only when the gland is small or medium sized [33]. Available meta-analyses indicate that although HoLRP is a surgical technique that requires longer operations time (17.7-31.0 versus $43.4-57.8 \mathrm{~h}$ ), the time of hospitalization after the procedure is shorter (27.6-59.0 versus 48.3-85.5 d) [34]. Long-term observations have shown that in patients who underwent treatment for prostate of volume more than $100 \mathrm{ml}$ outcomes and the necessity of reoperation are at a similar level as after adenomectomy [35]. Recent study comparing HoLEP with TURP, showed slightly better postoperative results in during 12-month fol- low-up in HoLEP group, as well as significantly better perioperative results and similarly low complication rates. However, the operative time and the incidence of postoperative dysuria favoured TURP [36].

Vaporisation (ThuVAP), vaporesection (ThuVARP), vapoenucleation (ThuVEP) and enucleation of the prostate (ThuLEP) with thulium laser are also effective and promising techniques. The results of a randomized study, which compared ThuVEP and HoLRP, indicated that during the 3 month follow-up observation both methods yield comparable improvement in urodynamic parameters, and in the case of ThuVEP, lower blood loss during surgery was observed [37]. During vapoenucleation of big prostates (average volume adenoma $-108,6 \mathrm{~mL}$ ) $86 \%$ reduction in prostate volume assessed by TRUS was achieved and a 88\% decrease in PSA levels was observed [38]. Recent trial showed that thulium laser resection of the prostate is safe, feasible, and efficient alternative to TURP for treating patients with $\mathrm{BPH} \mathrm{BPH}$ demonstrating reliable perioperative safety, fewer complications, comparable efficacy, but longer operative time [39]. However, thulium lasers do not allow lithotripsy which limits their application and usefulness. Complications profile after laser treatments is more favourable than after classic procedures. TURP syndrome was not observed after laser procedures and only few cases of prostate capsule perforation were reported [20, 22, 23]. The incidence of urinary incontinence after KTP PVP is $1.4 \%, 0.7 \%$ after LBO PVP, after diode PVP ranges from 0-10\%, and after HoLEP is about $0 \%$ while after TURP is $3 \%$ [40-44]. Retrograde ejaculation occurs at a similar level in laser and TURP groups and is observed in approximately $50 \%$ of cases. Narrowing of the bladder neck was observed in $3.6 \%$ of patients after LBO PVP and in $7.4 \%$ of patients after TURP $[20,22]$. In a recent large analysis of complications after classic TURP and laser transurethral resection of the prostate (L-TURP) demonstrated a modest benefit for L-TURP compared to TURP patients. Overall complication rates, haematuria and necessity of blood transfusion were comparable, however, infections were significantly more frequent in TURP group [45]. In other recent study, which compared intraoperative, early, and late postoperative complications after procedures in which various laser devices were used, it was shown that with the exception of re-catheterization, no significant difference in the rate of complications was observed. Recatheterization was the most frequent complication when diode laser was used [46]. A case of massive irrigant fluid leakage into the retroperitoneal space leading to intestinal paralysis and intraabdominal hypertension after holmium laser enucleation of the prostate has been recently published [47]. 
Laser applications in treatment of patients with urolithiasis

Modern laser techniques are an indispensable tool for treating patients with urolithiasis [48]. The advancement of the new generation ureteroscopes and the increasing power of the lasers allow lithotripsy of larger concrements to be shorter. Over $90 \%$ of lithotripsy procedures are successful [49]. The effectiveness and safety of laser lithotripsy has been proven in multiple studies regarding symptomatic ureteral stones in every location, treatment of pregnant women, overweight/obese patient and children of all ages [50, 51, 52].

It was shown in the literature that the Ho:YAG laser is a suitable tool to disintegrate ureteral calculi irrespectively of it's location [53]. This type of laser is also adequate tool for laser lithotripsy of ureteral post-SWL (shock wave lithotripsy) steinstrasse [54]. For some cases with multiple intrarenal calculi, ureteroscopy with Ho:YAG laser lithotripsy can be an alternative to ESWL or PNL, with acceptable efficacy and low morbidity [48]. It has been proven that both laser lithotripsy and pneumatic lithotripsy are equally safe and efficient for stone fragmentation, thus laser lithotripsy is associated with lower stone migration rate and easier retrieval of stone fragments [3]. It is also shown that laser lithotripsy is a superior method in costeffectiveness analysis compering to SWL for renal stones $<1.5 \mathrm{~cm}[55]$.

Endopielotomy may be also performed using a laser. It is comparably efficient and as safe as open pyeloplasty procedures however, some limitations should be noted. The facts that stricture shouldn't be longer than $2 \mathrm{~cm}$ and the operated kidney should be free of stones should be taken into consideration during qualification for treatment. The incision should be made laterally, so as not to damage possible crossing vessels $[49,56]$.

\section{Laser applications in treatment of patients with} bladder cancer and strictures of the urinary tract

Laser techniques have also found their place in the treatment of patients with tumours of the urinary bladder. First attempts to use laser in bladder cancer (BC) therapy were published by Staehler and Hofstetter in 1979 [57]. However, first large report on laser use in BC therapy was published by Beer in 1989 [58]. Despite promising outcomes, this method was abandoned for years. The reason for that might be possible bowel injury while using deep penetrating $\mathrm{Nd}$ :YaG laser [59]. Nowadays with introduction of new devices, laser resection techniques for blad- der tumor are coming back $[60,61]$. Several reports suggest the superiority of the laser method over TURBT, because it seems that a recurrence of cancer after laser treatments is not more frequent than after TURBT and complication rates seem to be lower after modern laser procedures when compared to TURBT $[49,62]$. In available studies regarding $\mathrm{BC}$ laser resections only 7 complications in total were mentioned [62]. Neither deaths, nor acute bleeding has been mentioned in any of the reports. Unfortunately, in available literature most studies are nonrandomized. In addition, there are no studies that compare different methods.

Laser techniques allow laser vaporization (LV), en bloc resection of $\mathrm{BC}$ and $\mathrm{BC}$ ablation. $\mathrm{LV}$ is suitable as an outpatient procedure because it does not require general anaesthesia. In some reports $L V$ was performed only with topical lidocaine yielding a good effect [63]. However, staging of BC is impossible after $\mathrm{LV}$, therefore, $\mathrm{LV}$ is not recommended for the treatment of primary $\mathrm{BC}$. $\mathrm{BC}$ en bloc resection is a method that in contrast to LV may provide oncological radicality. It consists of superficial circular incision around the tumor keeping in a distance of approximately $2-5 \mathrm{~mm}$ from tumour. With the aid of this marking line, the tumor is afterwards extracted by blunt dissection. The correct depth is reached when striated fibres of detrusor muscle are seen [64]. Laser operations of BC seem to be an interesting alternative to classic TURBs, but still their potential needs to be proven in larger prospective randomized controlled studies with long-term follow-up. Future expectations will show whether en bloc resection of $\mathrm{BC}$ are preferable over the traditional "incise and scatter" resection technique which is contrary to all accepted oncological surgical principles [59]. BC ablation is also an option especially in low-grade nonmuscle invasive bladder cancers (NMIBC) in elderly patients. The procedure seems to be effective, welltolerated, associated with a low risk of complications and can be successfully delivered in an outpatient setting [65, 66]. In addition, hexylaminolevulinate (HAL) photodynamic diagnosis (PDD)-assisted TURBT is also worth mentioning. This fluorescence using method helps to reveal lesions that may not be seen with standard white light cystoscopy. However, despite offering a more accurate diagnostic assessment of a bladder tumour, HAL-PPDD does not lead to lower recurrence rates of newly presenting NMIBC compared with the best current standard of care $[67,68]$.

Urethral strictures, even though optical or blind urethrotomy remains the gold standard procedures, can be also operated with laser technology. Endourethrotomy with laser is minimally invasive, and 
has similar or even superior effectiveness and safety compared with conventional methods [69, 70, 71]. Laser endourethrotomy is also proven to be shorter procedure than conventional methods [72]. The Ho:YAG laser offers a significant advantage with its coagulation ability. Laser efficiently removes scarred tissues by vaporization with minimal thermal damage to adjacent tissues [73]. In long strictures $(>1.5 \mathrm{~cm})$ results of laser endourethrotomy are worse, however, therapeutically effective [49, 74]. Although the role of laser urethrotomy in strictures management is not yet defined, may be a good alternative to urethroplasty especially in patients with high comorbidity who are not suitable for open operations.

\section{CONCLUSIONS}

Laser techniques are versatile tools in urology. Particularly significant is their use in patients with diseases of the prostate. Promising therapeutic effects of laser procedures tend to demonstrate their usage in treatment of patients with other diseases.

\section{CONFLICTS OF INTEREST}

The authors declare no conflicts of interest.

\section{References}

1. Staehler G, Hofstetter A, Gorisch W, Keiditsch E, Mussiggang M. Endoscopy in experimental urology using an argonlaser beam. Endoscopy. 1976; 8: 1-4.

2. Gravas S, Bachmann A, Reich O, Roehrborn CG, Gilling PJ, De La Rosette J. Critical review of lasers in benign prostatic hyperplasia (BPH). BJU Int. 2011; 107: 1030-1043.

3. Ganesamoni R, Sabnis RB, Mishra S, et al. Prospective randomized controlled trial comparing laser lithotripsy with pneumatic lithotripsy in miniperc for renal calculi. J Endourol. 2013; 27: 1444-1449.

4. Qiu J, Teichman JM, Wang T, et al. Femtosecond laser lithotripsy: feasibility and ablation mechanism. J Biomed Opt. 2010; 15: 028001.

5. Vassar GJ, Chan KF, Teichman JM, et al. Holmium: YAG lithotripsy: photothermal mechanism. J Endourol. 1999; 13: 181-190.

6. Committee AUAPG. AUA guideline on management of benign prostatic hyperplasia (2003). Chapter 1: Diagnosis and treatment recommendations. J Urol. 2003; 170: 530-547.

7. Zarrabi A, Gross AJ. The evolution of lasers in urology. Ther Adv Urol. 2011; 3: 81-89.

8. Kuntz RM. Current role of lasers in the treatment of benign prostatic hyperplasia (BPH). Eur Urol. 2006; 49: 961-969.

9. Wosnitzer MS, Rutman MP. KTP/LBO laser vaporization of the prostate. Urol Clin North Am. 2009; 36: 471-483.

10. Heinrich E, Wendt-Nordahl G, Honeck P, et al. $120 \mathrm{~W}$ lithium triborate laser for photoselective vaporization of the prostate: comparison with $80 \mathrm{~W}$ potassium-titanyl-phosphate laser in an ex-vivo model. J Endourol. 2010; 24: 75-79.

11. Chiang PH, Chen $\mathrm{CH}$, Kang $\mathrm{CH}$, Chuang YC. GreenLight HPS laser 120-W versus diode laser 200-W vaporization of the prostate: comparative clinical experience. Lasers Surg Med. 2010; 42: 624-629.

12. de Lucia C, Femminella GD, Rengo G, et al. Risk of acute myocardial infarction after transurethral resection of prostate in elderly. BMC Surg. 2013; 13 Suppl 2: S35.

13. Capitan C, Blazquez C, Martin MD, Hernandez V, de la Pena E, Llorente C. GreenLight HPS 120-W laser vaporization versus transurethral resection of the prostate for the treatment of lower urinary tract symptoms due to benign prostatic hyperplasia: a randomized clinical trial with 2-year follow-up. Eur Urol. 2011; 60: 734-739.

14. Tugcu V, Tasci Al, Sahin S, Zorluoglu F. Comparison of photoselective vaporization of the prostate and transurethral resection of the prostate: a prospective nonrandomized bicenter trial with 2-year follow-up. J Endourol. 2008; 22: 1519-1525.

15. Madersbacher S, Lackner J, Brossner C, et al. Reoperation, myocardial infarction and mortality after transurethral and open prostatectomy: a nation-wide, long-term analysis of 23,123 cases. Eur Urol. 2005; 47: 499-504.

16. Elshal AM, Elmansy HM, Elhilali MM. Transurethral laser surgery for benign prostate hyperplasia in octogenarians: safety and outcomes. Urology. 2013; 81: 634-639.

17. Reich O, Gratzke C, Bachmann A, et al. Morbidity, mortality and early outcome of transurethral resection of the prostate: a prospective multicenter evaluation of 10,654 patients. J Urol. 2008; 180: 246-249.

18. Toepfer NJ, Baylor K, Henry Y, Simmons J, Berger PB. The effect of antiplatelet and anticoagulant therapy on the clinical outcome of patients undergoing ureteroscopy. Urology. 2013; 82: 773-779.

19. Tasci Al, Tugcu V, Sahin S, Zorluoglu F. Rapid communication: photoselective vaporization of the prostate versus transurethral resection of the prostate for the large prostate: a prospective nonrandomized bicenter trial with 2-year follow-up. J Endourol. 2008; 22: 347-353.

20. Al-Ansari A, Younes N, Sampige VP, et al. GreenLight HPS 120-W laser vaporization versus transurethral resection of the prostate for treatment of benign prostatic hyperplasia: a randomized clinical trial with midterm follow-up. Eur Urol. 2010; 58: 349-355.

21. Bouchier-Hayes DM, Anderson $P$, Van Appledorn S, Bugeja P, Costello AJ. KTP laser versus transurethral resection: early results of a randomized trial. J Endourol. 2006; 20: 580-585.

22. Horasanli K, Silay MS, Altay B, Tanriverdi O, Sarica K, Miroglu C. Photoselective potassium titanyl phosphate (KTP) laser vaporization versus transurethral resection of the prostate for prostates larger than $70 \mathrm{~mL}$ : a short-term prospective randomized trial. Urology. 2008; 71: 247-251. 
23. Skolarikos A, Papachristou C, Athanasiadis G, Chalikopoulos D, Deliveliotis C, Alivizatos G. Eighteen-month results of a randomized prospective study comparing transurethral photoselective vaporization with transvesical open enucleation for prostatic adenomas greater than $80 \mathrm{cc}$. J Endourol. 2008; 22: 2333-2340.

24. Telli O, Okutucu TM, Suer E, et al. A prospective, randomized comparative study of monopolar transurethral resection of the prostate versus photoselective vaporization of the prostate with GreenLight 120-W laser, in prostates less than $80 \mathrm{cc}$. Ther Adv Urol. 2015; 7: 3-8.

25. Altay B, Erkurt B, Kiremit MC, Guzelburc V, Boz MY, Albayrak S. 180-W XPS GreenLight laser vaporization for benign prostate hyperplasia: 12-month safety and efficacy results for glands larger than $80 \mathrm{~mL}$ Lasers Med Sci. 2015; 30: 317-323.

26. Bachmann A, Tubaro A, Barber N, et al. 180-W XPS GreenLight laser vaporisation versus transurethral resection of the prostate for the treatment of benign prostatic obstruction: 6-month safety and efficacy results of a European Multicentre Randomised Trial--the GOLIATH study. Eur Urol. 2014; 65: 931-942.

27. Bachmann A, Tubaro A, Barber N, et al. A European Multicenter Randomized Noninferiority Trial Comparing 180 W GreenLight XPS Laser Vaporization and Transurethral Resection of the Prostate for the Treatment of Benign Prostatic Obstruction: 12-Month Results of the GOLIATH Study. J Urol. 2015; 193: 570-578.

28. Elshal AM, Elkoushy MA, Elmansy HM, Sampalis J, Elhilali MM. Holmium:YAG transurethral incision versus laser photoselective vaporization for benign prostatic hyperplasia in a small prostate. J Urol. 2014; 191: 148-154.

29. Guo S, Muller G, Bonkat, G, et al. Greenlight laser versus Diode laser vaporization of the prostate: 3-year results of a prospective non-randomized study. J Endourol. 2014.

30. Razzaghi MR, Mazloomfard MM, Mokhtarpour H, Moeini A. Diode laser $(980 \mathrm{~nm}$ ) vaporization in comparison with transurethral resection of the prostate for benign prostatic hyperplasia: randomized clinical trial with 2-year follow-up. Urology. 2014; 84: 526-532.

31. Elmansy HM, Elzayat E, Elhilali MM. Holmium laser ablation versus photoselective vaporization of prostate less than $60 \mathrm{cc}$ : long-term results of a randomized trial. J Urol. 2010; 184: 2023-2028

32. Mottet N, Anidjar M, Bourdon O, et al. Randomized comparison of transurethral electroresection and holmium: YAG laser vaporization for symptomatic benign prostatic hyperplasia. J Endourol. 1999; 13: 127-130.

33. Westenberg A, Gilling P, Kennett K, Frampton C, Fraundorfer M. Holmium laser resection of the prostate versus transurethral resection of the prostate: results of a randomized trial with 4-year minimum long-term followup. J Urol. 2004; 172: 616-619.

34. Tan A, Liao C, Mo Z, Cao Y. Meta-analysis of holmium laser enucleation versus transurethral resection of the prostate for symptomatic prostatic obstruction. Br J Surg. 2007; 94: 1201-1208.

35. Gilling PJ, Aho TF, Frampton CM, King CJ, Fraundorfer MR. Holmium laser enucleation of the prostate: results at 6 years. Eur Urol. 2008; 53: 744-749.

36. Yin L, Teng J, Huang CJ, Zhang X, Xu D. Holmium laser enucleation of the prostate versus transurethral resection of the prostate: a systematic review and metaanalysis of randomized controlled trials. J Endourol. 2013; 27: 604-611.

37. Shao $Q$, Zhang $F B$, Shang $D H$, Tian $Y$. [Comparison of holmium and thulium laser in transurethral enucleation of the prostate]. Zhonghua Nan Ke Xue. 2009; 15: 346-349.

38. Bach T, Xia SJ, Yang Y, et al. Thulium: YAG 2 mum cw laser prostatectomy: where do we stand? World J Urol. 2010; 28: 163-168.

39. Tang K, Xu Z, Xia D, et al. Early outcomes of thulium laser versus transurethral resection of the prostate for managing benign prostatic hyperplasia: a systematic review and meta-analysis of comparative studies. J Endourol. 2014; 28: 65-72.

40. Choi SW, Choi YS, Bae WJ, et al. 120 W Greenlight HPS Laser Photoselective Vaporization of the Prostate for Treatment of Benign Prostatic Hyperplasia in Men with Detrusor Underactivity. Korean J Urol. 2011; 52: 824-828.

41. Te AE, Malloy TR, Stein BS, Ulchaker JC, Nseyo UO, Hai MA. Impact of prostatespecific antigen level and prostate volume as predictors of efficacy in photoselective vaporization prostatectomy: analysis and results of an ongoing prospective multicentre study at 3 years. BJU Int. 2006; 97: 1229-1233.

42. Clemente Ramos LM. High power 980 nm diode laser: preliminary results in the treatment of benign prostatic hyperplasia. Arch Esp Urol. 2009; 62: 125-130.

43. Erol A, Cam K, Tekin A, Memik O, Coban S, Ozer Y. High power diode laser vaporization of the prostate: preliminary results for benign prostatic hyperplasia. J Urol. 2009; 182: 1078-1082.

44. Rivera ME, Frank I, Viers BR, Rangel LJ, Krambeck AE. Holmium laser enucleation of the prostate and perioperative diagnosis of prostate cancer: an outcomes analysis. J Endourol. 2014; 28: 699-703.

45. Larouche A, Becker A, Schiffmann J, et al. Comparison between complication rates of laser prostatectomy electrocautery transurethral resection of the prostate: A population-based study. Can Urol Assoc J. 2014; 8: E419-424.

46. Lee WC, Lin YH, Hou CP, et al. Prostatectomy using different lasers for the treatment of benign prostate hyperplasia in aging males. Clin Interv Aging. 2013; 8: 1483-1488.

47. Richter T, Huebler M. Acute abdominal compartment syndrome as a complication of Holmium laser enucleation of the prostate: a case report. BMC Anesthesiol. 2014; 14: 32.

48. Breda A, Ogunyemi O, Leppert JT, Schulam PG. Flexible ureteroscopy and laser lithotripsy for multiple unilateral intrarenal stones. Eur Urol. 2009; 55: 1190-1196.

49. Herrmann TR, Liatsikos EN, Nagele U, Traxer O, Merseburger AS, European Association of U. [European Association of Urology guidelines on laser technologies]. Actas Urol Esp. 2013; 37: 63-78.

50. Adanur S, Ziypak T, Bedir F, et al. Ureteroscopy and holmium laser lithotripsy: is this procedure safe in pregnant women with ureteral stones at different locations? Arch Ital Urol Androl. 2014; 86: 86-89.

51. Chew BH, Zavaglia B, Paterson RF, et al. A multicenter comparison of the safety and effectiveness of ureteroscopic laser lithotripsy in obese and normal weight patients. J Endourol. 2013; 27: 710-714. 
52. Uygun I, Okur MH, Aydogdu B, Arayici Y, Isler B, Otcu S. Efficacy and safety of endoscopic laser lithotripsy for urinary stone treatment in children. Urol Res. 2012; 40: 751-755.

53. Khoder WY, Bader M, Sroka R, Stief C, Waidelich R. Efficacy and safety of Ho:YAG laser lithotripsy for ureteroscopic removal of proximal and distal ureteral calculi. BMC Urol. 2014; 14: 62.

54. Feng $C$, Wu Z, Jiang $H$, Ding $Q$, Gao P. Ureteroscopic Holmium:YAG laser lithotripsy is effective for ureteral steinstrasse post-SWL. Minim Invasive Ther Allied Technol. 2013; 22: 279-282.

55. Cone EB, Eisner BH, Ursiny M, Pareek G. Cost-effectiveness comparison of renal calculi treated with ureteroscopic laser lithotripsy versus shockwave lithotripsy. J Endourol. 2014; 28: 639-643.

56. Emiliani E, Breda A. Laser endoureterotomy and endopyelotomy: an update. World J Urol. 2014; 33: 583-587.

57. Staehler G, Hofstetter A. Transurethral laser irradiation of urinary bladder tumors. Eur Urol. 1979; 5: 64-69.

58. Beer M, Jocham D, Beer A, Staehler G. Adjuvant laser treatment of bladder cancer: 8 years' experience with the Nd-YAG laser $1064 \mathrm{~nm}$. Br J Urol. 1989; 63: 476-478.

59. Kramer MW, Bach T, Wolters M, et al. Current evidence for transurethral laser therapy of non-muscle invasive bladder cancer. World J Urol. 2011; 29: 433-442.

60. Liu H, Wu J, Xue S, et al. Comparison of the safety and efficacy of conventional monopolar and 2-micron laser transurethral resection in the management of multiple nonmuscle-invasive bladder cancer. J Int Med Res. 2013; 41: 984-992.

61. Yang D, Xue B, Zang Y, et al. Efficacy and safety of potassium-titanyl- phosphate laser vaporization for clinically non-muscle invasive bladder cancer. Urol J. 2014; 11: 1258-1263.

62. Kramer MW, Wolters M, Cash $\mathrm{H}$, et al. Current evidence of transurethral Ho:YAG and Tm:YAG treatment of bladder cancer: update 2014. World J Urol. 2015; 33: 571-579.

63. Jonler M, Lund L, Bisballe S. Holmium:YAG laser vaporization of recurrent papillary tumours of the bladder under local anaesthesia. BJU Int. 2004; 94: 322-325.

64. Wolters M, Kramer MW, Becker JU, et al. Tm:YAG laser en bloc mucosectomy for accurate staging of primary bladder cancer: early experience. World J Urol. 2011; 29: 429-432.

65. Syed HA, Talbot N, Abbas A, et al. Flexible cystoscopy and Holmium:Yttrium aluminum garnet laser ablation for recurrent nonmuscle invasive bladder carcinoma under local anesthesia. J Endourol. 2013; 27: 886-891.

66. Wong KA, Zisengwe G, Athanasiou T, O'Brien T, Thomas K. Outpatient laser ablation of non-muscle-invasive bladder cancer: is it safe, tolerable and costeffective? BJU Int. 2013; 112: 561-567.

67. O'Brien T, Ray E, Chatterton K, Khan MS, Chandra A, Thomas K. Prospective randomized trial of hexylaminolevulinate photodynamic-assisted transurethral resection of bladder tumour (TURBT) plus single-shot intravesical mitomycin $C$ vs conventional white-light TURBT plus mitomycin $C$ in newly presenting nonmuscle-invasive bladder cancer. BJU Int. 2013; 112: 1096-1104.
68. Lapini A, Minervini A, Masala A, et al. A comparison of hexaminolevulinate (Hexvix ${ }^{\circledR}$ ) fluorescence cystoscopy and white-light cystoscopy for detection of bladder cancer: results of the HeRo observational study. Surg Endosc. 2012; 26: 3634-3641.

69. Kamp S, Knoll T, Osman MM, Kohrmann KU, Michel MS, Alken P. Low-power holmium:YAG laser urethrotomy for treatment of urethral strictures: functional outcome and quality of life. J Endourol. 2006; 20: 38-41.

70. Gupta NP, Ansari MS. Holmium laser core through internal urethrotomy with explantation of UroLume stent. An ideal approach for a complicated posterior urethral stricture. Int J Urol. 2004; 11: 343-344.

71. Dogra PN, Ansari MS, Gupta NP, Tandon S. Holmium laser core-through urethrotomy for traumatic obliterative strictures of urethra: initial experience. Urology. 2004; 64: 232-235.

72. Atak M, Tokgoz H, Akduman B, et al. Lowpower holmium:YAG laser urethrotomy for urethral stricture disease: comparison of outcomes with the cold-knife technique. Kaohsiung J Med Sci. 2011; 27: 503-507.

73. Dutkiewicz SA, Wroblewski M. Comparison of treatment results between holmium laser endourethrotomy and optical internal urethrotomy for urethral stricture. Int Urol Nephrol. 2012; 44: 717-724.

74. Liu Q, Ma W, Li X, et al. Holmium laser endourethrotomy for the treatment of long-segment urethral strictures: a retrospective study of 190 patients. Urol J. 2014; 11: 1264-1270. 